\title{
Acta
Biochimica
Polonica
}

Vol. 50 No. $3 / 2003$

$799-806$

QUARTERLY

\section{X-band and S-band EPR detection of nitric oxide in murine endotoxaemia using spin trapping by ferro-di( $N$-(dithio- carboxy)sarcosine) ${ }^{\star *}$}

\author{
Przemyslaw M. Plonka ${ }^{1 凶}$, Magdalena Wisniewska ${ }^{1}$, Stefan Chlopicki ${ }^{2}$, Martyna \\ Elas $^{1,3}$ and Gerald M. Rosen ${ }^{3,4}$
}

${ }^{1}$ Department of Biophysics, Faculty of Biotechnology, Jagiellonian University, Kraków, Poland;

${ }^{2}$ Department of Pharmacology, Collegium Medicum of the Jagiellonian University, Kraków, Poland; ${ }^{3}$ The Center for Low Frequency EPR Imaging for In Vivo Physiology, The University of Chicago, IL, U.S.A., and University of Maryland, Baltimore, Baltimore, MD, U.S.A.;

${ }^{4}$ Department of Pharmaceutical Sciences, School of Pharmacy, University of Maryland, Baltimore, MD, The Medical Biotechnology Center, University of Maryland Biotechnology Institutes, Baltimore, MD, U.S.A.

Received: 30 May, 2003; revised: 23 August, 2003; accepted: 04 September, 2003

Key words: oxidative stress, NO-metry, NOS, septic shock, lung injury, DTCS

\begin{abstract}
Ammonium salt of $\mathrm{N}$-(dithiocarboxy)sarcosine (DTCS) chelated to ferrous salt was tested as an NO-metric spin trap at room temperature for ex vivo measurement of ${ }^{\circ}$ NO production in murine endotoxaemia. In a chemically defined in vitro model system EPR triplet signals of NO-Fe(DTCS) $)_{2}$ were observed for as long as 3 hours, only if samples were reduced with sodium dithionite. This procedure was not necessary for
\end{abstract}

\footnotetext{
${ }^{\star}$ Presented at the XXX Winter School of Faculty of Biotechnology, Jagiellonian University, Kościelisko, Poland, 28th February-4th March, 2003.

*Preliminary report of this work was presented by M.W. at the XVIII Winter School of Faculty of Biotechnology, JU, "New methods and techniques in molecular biology and biotechnology", April 21-26, 2001, Zakopane, Poland

This research was supported in part by a grant from the National Institutes of Health, U.S.A., RR-12257 to G.M.R., and by a grant from the State Committee for Scientific Research (KBN, Poland) P05A 10112 to S.C.

${ }^{凶}$ Author for correspondence: P. Plonka, Department of Biophysics, Faculty of Biotechnology, Jagiellonian University, Gronostajowa 7, 30-387 Kraków, Poland; phone: (48 12) 252 6350, fax: (48 12) 252 6907, e-mail: mieszko@awe.mol.uj.edu.pl
}

Abbreviations: DETC, diethyldithiocarbamate; DPPH, 1,1-diphenyl-2-picrylhydrazyl; DTCS, $N$-(dithiocarboxy)sarcosine; EPR, electron paramagnetic resonance; LPS, lipopolysaccharide; MGD, $N$-methyl-D-glucamine dithiocarbamate; NOS, nitric oxide synthase; PBS, phosphate buffered saline. 
the ex vivo detection of ${ }^{\circ} \mathrm{NO}$ in endotoxaemic liver homogenates at X-band or in the whole intact organs at S-band, whereas only a weak signal was observed in endotoxaemic lung. These results suggest that in endotoxaemia not only high level of ${ }^{\bullet} \mathrm{NO}$, but also the redox properties of liver and lung might determine the formation of complexes of ${ }^{\circ} \mathrm{NO}$ with a spin trap. Nevertheless, both $\mathrm{S}$ - and X-band EPR spectroscopy is suitable for ${ }^{\circ}$ NO-metry at room temperature using Fe(DTCS) $)_{2}$ as the spin trapping agent. In particular, S-band EPR spectroscopy enables the detection of ${ }^{\circ} \mathrm{NO}$ production in a whole organ, such as murine liver.

Nitric oxide ( $\left.{ }^{\bullet} \mathrm{NO}\right)$ is produced by a family of heme-containing monooxygenases, nitric oxide synthases (NOS, EC 1.14.13.39), during the oxidative metabolism of L-arginine to L-citrulline. The discovery of enzymatic production of ${ }^{\bullet}$ NO has opened up a new era in our understanding of the role of free radicals in the control of physiological functions (Moncada et al., 1991) and, not surprisingly, evoked a need to directly measure ${ }^{\bullet} \mathrm{NO}$ in vivo, in situ in real time and at the site of its production. Of the three isoforms of NOS, the inducible isoezyme (NOS-2) has been of interest to us, as a variety of cytokines and mitogens can up-regulate the biosynthesis of this enzyme in a wide variety of cells (Thiemermann, 1997). Furthermore, NOS-2 produces a high flux of -NO for prolonged periods of time, making -NO synthesized by NOS-2 a convenient target to develop NO-metric methods.

Due to the odd number of electrons, ${ }^{\bullet} \mathrm{NO}$ can be detected using electron paramagnetic resonance (EPR) spectroscopy. Direct detection of NO by EPR spectroscopy is only possible in the gaseous phase under low pressure (Weil et al., 1994). To be measured in biological systems, i.e. at low concentrations in aqueous solutions, ${ }^{\circ} \mathrm{NO}$ has to react with a probe, e.g. a spin-trap, and form a paramagnetic, EPR-detectable compound: a spin adduct (Rosen et al., 1999). Importantly, some biological targets of ${ }^{\bullet} \mathrm{NO}$, such as heme-containing proteins (e.g. haemoglobin and myoglobin), and nonheme iron, form paramagnetic, EPR-detectable complexes with ${ }^{\bullet} \mathrm{NO}$ (e.g. nitrosohaemoglobin, nitrosomyoglobin, dinitrosyl-iron complexes). As their EPR signal becomes observable at the temperature of liquid nitrogen $(77 \mathrm{~K})$, they are not applicable to detection of
-NO in vivo. This is why alternative methods have been developed, such as the use of pre-formed ferrous-complexes, which spintrap ${ }^{\bullet} \mathrm{NO}$, and yield a stable ${ }^{\circ} \mathrm{NO}-\mathrm{Fe}$ complex (McDonald et al., 1965). In the case of diethyldithiocarbamate (DETC), however, the complex with iron(II) is insoluble in water, requiring the introduction of DETC and ferrous salts separately into an animal (Kubrina et al., 1992; Vanin et al., 1989). Other iron(II) chelates, such as sodium $N$-methyl-D-glucamine dithiocarbamate ((Na) ${ }_{2} \mathrm{MGD}$ ) (Shinobu et al., 1984) and sodium $N$-(dithiocarboxy)sarcosine ((Na) $)_{2}$ DTCS), form water-soluble complexes with iron(II) that allow detection of ${ }^{\bullet} \mathrm{NO}$ in endotoxaemia in vivo, in situ (Yoshimura et $a l ., 1996)$ and in solid tumors (Doi et al., 1999). The iron(II) complexes of DTCS, together with MGD, display specificity towards - NO similar to that found for Fe(DETC) $)_{2}$. However, in contrast to $\mathrm{Fe}(\mathrm{DETC})_{2}$, both $\mathrm{Fe}(\mathrm{DTCS})_{2}$ and $\mathrm{Fe}(\mathrm{MGD})_{2}$ can be used for the detection of nitric oxide under in vivo conditions. Importantly, $\mathrm{Fe}(\mathrm{DTCS})_{2}$ is more hydrophobic than $\mathrm{Fe}(\mathrm{MGD})_{2}$, and consequently it remains in vivo for a longer period of time. Therefore, Fe(DTCS) 2 may be used at lower concentrations than is required for $\mathrm{Fe}(\mathrm{MGD})_{2}$. The efficiency and kinetics of ${ }^{\bullet} \mathrm{NO}$ spin trapping by both substances were exhaustively characterized by Pou et al. (1999).

One of the drawbacks of $(\mathrm{Na})_{2} \mathrm{DTCS}$ is the hygroscopic nature of this compound, making it impractical to handle. Recent studies, however, have found that $\left(\mathrm{NH}_{4}\right)_{2}$ DTCS is less hygroscopic than $(\mathrm{Na})_{2} \mathrm{DTCS}$. Upon forming $\mathrm{Fe}(\mathrm{DTCS})_{2}$, reaction with ${ }^{\circ} \mathrm{NO}$ affords NO-Fe(DTCS) $)_{2}$ that is stable in vivo, with a half-life of 41 minutes (Pou et al., 1999). 
Drawing upon earlier studies, we explored the potential of using $\mathrm{Fe}(\mathrm{DTCS})_{2}$ as an in vivo spin trap for ${ }^{\circ} \mathrm{NO}$ by analyzing production of this free radical in murine endotoxaemic liver and lung using S- and X-band EPR spectroscopy.

\section{MATERIALS AND METHODS}

Reagents. The ammonium salt of DTCS was synthesized according to Pou et al. (1999). Ferrous sulphate $\left(\mathrm{FeSO}_{4} \times 7 \mathrm{H}_{2} \mathrm{O}\right)$, sodium dithionite $\left(\mathrm{Na}_{2} \mathrm{~S}_{2} \mathrm{O}_{4}\right)$, lipopolysaccharide (LPS) from Escherichia coli (serotype 027:B8) were obtained from Sigma Chem. Co. (Baltimore, MD, U.S.A.). Phosphate buffered saline (PBS) was purchased from Wytwórnia Surowic i Szczepionek, BIOMED (Lublin, Poland) and sodium nitrite $\left(\mathrm{NaNO}_{2}\right)$ from Zakłady Azotowe (Chorzów, Poland).

In vitro measurements of $\mathrm{NO}-\mathrm{Fe}(\mathrm{DTCS})_{2}$.

All concentrations are given as final concentrations in a sample. Solutions were prepared in phosphate buffered saline (PBS) bubbled at least for 30 min with $\mathrm{N}_{2}$ to remove $\mathrm{O}_{2}$. Solution of $\mathrm{FeSO}_{4} \times 7 \mathrm{H}_{2} \mathrm{O}(0.5 \mathrm{mg} / \mathrm{ml})$ was added to a solution of $\left(\mathrm{NH}_{4}\right)_{2} \mathrm{DTCS}(3 \mathrm{mM})$, and, when necessary, reduced with sodium dithionite (5.8 $\mathrm{mg} / \mathrm{ml}$ ). This mixture was supplemented with a solution of ${ }^{\bullet} \mathrm{NO}(0.067 \mathrm{mM})$ obtained by reduction of a stoichiometric equivalent of sodium nitrite with an excess of sodium dithionite. The solutions were prepared shortly (2-3 $\mathrm{min}$ ) before experiments, and were mixed just before EPR measurement made in a standard flat quartz chamber $(0.2 \mathrm{ml})$. EPR spectroscopic measurements were carried out using an EPR X-band (9.5 GHz) spectrometer Varian E-103, equipped with a rectangular TE 102 resonant cavity, at ambient temperature. Instrumentation parameters are given in figure legends. For kinetic experiments, the EPR spectrum of NO-Fe(DT$\mathrm{CS})_{2}$, derived from the reaction of pre-formed Fe(DTCS) $)_{2}$ with ${ }^{\circ} \mathrm{NO}$, was recorded every 5 min, over at least $3 \mathrm{~h}$ after preparation. The po- sition of a free radical standard $(\mathrm{g}=2.004)$ was indicated by the EPR spectrum of a small powder sample of diphenylpicrylhydrazyl (DPPH). Experiments were conducted in triplicate.

Spin trapping of ${ }^{\bullet} \mathrm{NO}$ in murine lung and liver using $\mathrm{Fe}(\mathrm{DTCS})_{2}$. Endotoxaemia was induced in vivo in female C57BL/6 mice (Animal Breeding Facility of the Silesian Medical Academy, Katowice, Poland) by a single i.p. injection of $1 \mathrm{mg}$ of LPS dissolved in $0.5 \mathrm{ml}$ of PBS. EPR spectroscopic measurements were performed $6 \mathrm{~h}$ after LPS injection. One hour before euthanasia animals were given the complex of DTCS and Fe(II) (100 mM and 200 $\mathrm{mM}$, respectively) subcutaneously, in $0.5 \mathrm{ml}$ of PBS. Directly before injection the mixture was reduced with a tiny crystal of sodium dithionite, which resulted in the color change from brownish to yellow.

Measurements of EPR spectra at X-band were carried out in a similar way to those described above, but without additional reduction of the sample. Liver homogenate was prepared using a glass homogenizer. Whole, intact liver (about $1400 \mathrm{mg}$ ) and lung (about 400 $\mathrm{mg}$ ) ex vivo were measured at S-band. The whole organ was placed on a piece of plexiglass and covered with parafilm to prevent evaporation. EPR spectroscopic measurements were carried out using a home-modified EPR spectrometer (Radiopan, Poznań, Poland) equipped with a microwave bridge with a reference cavity (Jagmar, Kraków, Poland), magnetic field stabilizer (Technical University, Wrocław, Poland) and double-phase lock-in amplifier SR830DSP (Stanford, Sunnyvalley, CA, U.S.A.). The parameters of assay are given in figure legends. Spectra were taken three-four times every $20 \mathrm{~min}$. The first EPR spectrum was recorded not later than 5 min after animal euthanasia.

Experiments on animals were repeated four times ( 1 animal per experiment), with permission of the Permanent Rector Commission for Bioethics of Animal Investigation (permission number: 302/97). 


\section{RESULTS}

In the first set of experiments we analyzed the formation of NO-Fe(DTCS) $)_{2}$ in an aqueous solutions of a mixture of $\mathrm{Fe}(\mathrm{DTCS})_{2}$ and ${ }^{\circ} \mathrm{NO}$. A typical EPR spectrum of NO-Fe(DTCS) ${ }_{2}$ at $\mathrm{X}$-band, and ambient temperature is shown in Fig. 1. Only after additional reduction of the sample with dithionite was a strong nitrogen triplet of NO-Fe(DTCS $)_{2}(\mathrm{~g}=2.04 \pm 0.003$; $\mathrm{A}^{\mathrm{N}}=12.5 \pm 1 \mathrm{Gs}$ ) visible. This signal was shifted towards lower magnetic field, as compared with the free-radical signal $(g=2.004)$.
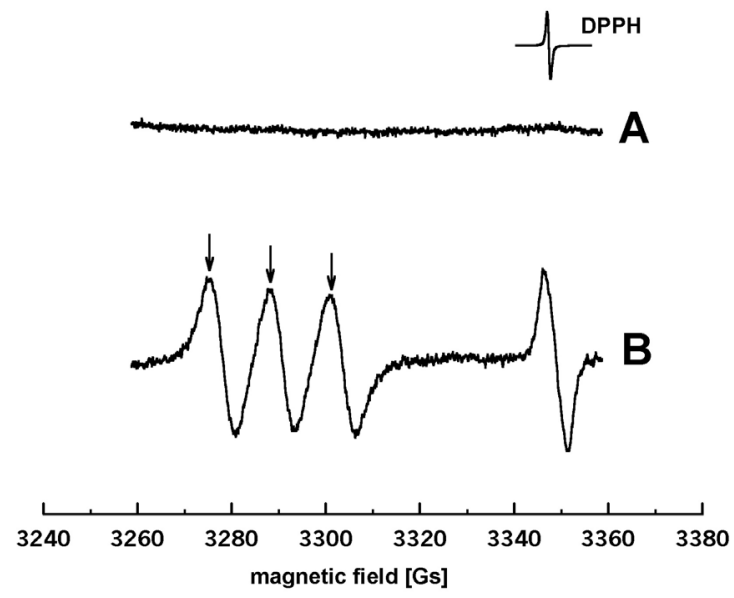

Figure 1. In vitro spin trapping of ${ }^{\circ} \mathrm{NO}$ by $\mathrm{Fe}(\mathrm{DTCS})_{2}$.

A mixture of ferrous sulphate and DTCS (3 mM/0.2 $\mathrm{mM}$ ) was mixed with a solution of sodium nitrite $(0.067$ $\mathrm{mM})$. The EPR triplet signal of NO-Fe(DTCS) $)_{2}$ complexes $\left(\mathrm{g}=2.04, \mathrm{~A}^{\mathrm{N}}=12.5 \mathrm{Gs}\right)$ became detectable only after additional reduction of the sample with sodium dithionite (about $60 \mathrm{mg} / \mathrm{ml}$ ). A free radical signal appeared in parallel to the triplet signal. The spectra were recorded at magnetic field $3309 \pm 50$ Gs, modulation amplitude $10 \mathrm{Gs}$, microwave power $-4 \mathrm{~mW}$ and frequency $9.47 \mathrm{GHz}$, gain 400000 , time constant $0.3 \mathrm{~s}$, and scan time $400 \mathrm{~s}$. DPPH - marks the position of free radical signal $(g=2.004)$, arrows - the ${ }^{14} \mathrm{~N}$ hyperfine splitting.

The EPR spectrum of NO-Fe(DTCS) $)_{2}$ decreased with time, as shown in Fig. 2. Three hours after mixing $\mathrm{Fe}(\mathrm{DTCS})_{2}$ and ${ }^{\circ} \mathrm{NO}$ the EPR spectrum was still detectable at room temperature, and the half-life of the spectrum was found to be $55 \pm 5 \mathrm{~min}$.

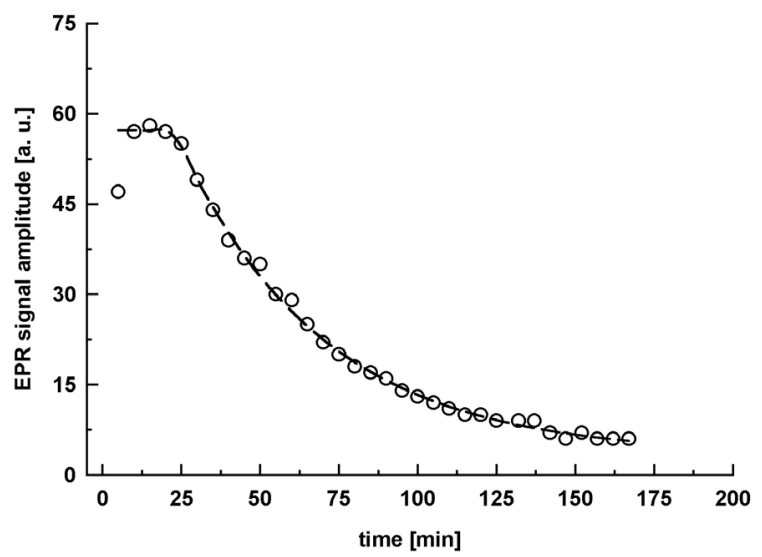

Figure 2. Kinetics of decomposition of NOFe(DTCS $)_{2}$ complexes measured by EPR spectroscopy.

The signal was registered every 5 min at instrumental parameters as in Fig. 1. The amplitude reached half of its maximal value ( $5 \mathrm{~min}$ ) on $55 \mathrm{~min}$ since mixing the solutions. Parameters - see Fig. 1.

Figure 3A is illustrative of the EPR spectrum of NO-Fe(DTCS) $)_{2}$ from a murine endotoxaemic liver homogenate (about $200 \mathrm{mg}$ ), recorded at ambient temperature, using X-band, 40 min after death of the animal. A weak, but measurable EPR spectrum of NO-Fe(DTCS) 2 was observed as long as $2 \mathrm{~h}$ after animal death (Fig. 3 B).

More important, however, was the finding of a robust EPR spectrum of NO-Fe(DTCS) 2 at S-band from an intact $1400 \mathrm{mg}$ murine liver, detected $6 \mathrm{~h}$ after LPS administration (Fig. 4A). The EPR spectrum remained detectable for at least $65 \mathrm{~min}$ after excision of the organ (Fig. 4B). The amplitude of the second line of hyperfine splitting diminished during this time from 10 to 1.75 a.u. However, in the lung, the EPR spectrum was considerably weaker (Fig. 5A, amplitude 0.78 a.u.), and disappeared much faster than that found in the liver (Fig. 5B). In other organs of similar size (heart, kidney) we were not able to detect NO-Fe(DTCS) $)_{2}$ complexes at room temperature (not shown). 


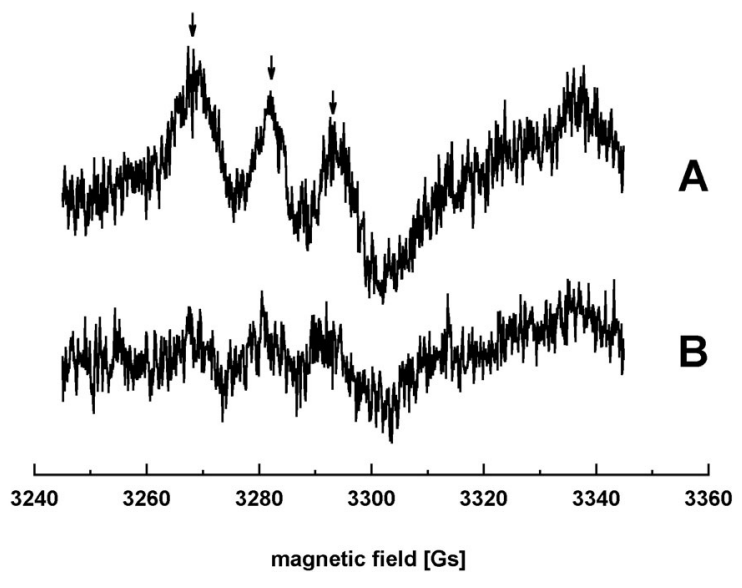

Figure 3. The EPR signal of homogenized murine liver at 6th hour of endotoxaemia (i.p. injection of $1 \mathrm{mg}$ LPS) observed 40 (A) and 120 (B) min after organ excision.

Fe(DTCS $)_{2}$ was injected 30 min before euthanasia. Parameters of measurements: magnetic field $3295 \pm 50$ Gs, modulation amplitude $10 \mathrm{Gs}$, microwave power $50 \mathrm{~mW}$ and frequency $9.47 \mathrm{GHz}$, gain 800000 , time constant $0.1 \mathrm{~s}$, and scan time $180 \mathrm{~s}$ (average of 3 records). Arrows indicate the ${ }^{14} \mathrm{~N}$ hyperfine splitting.
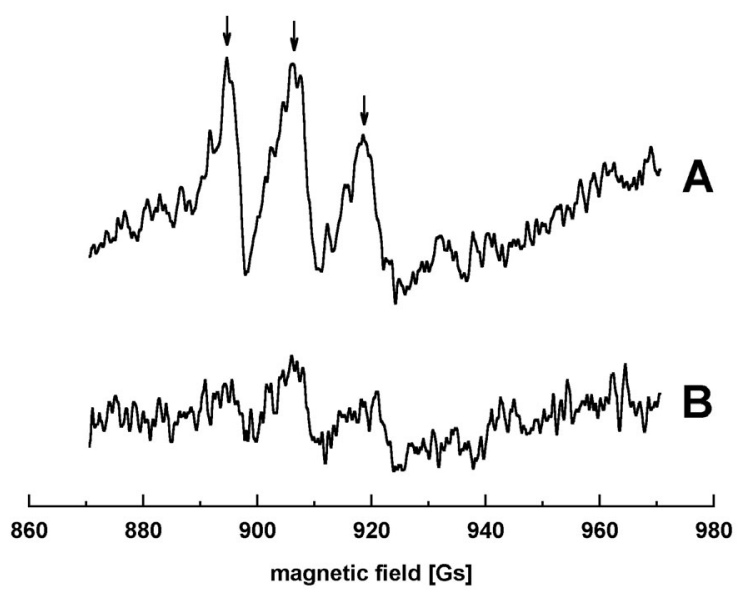

Figure 4. S-band EPR signals of whole murine liver (1400 $\mathrm{mg}$ ) isolated at 6th hour of endotoxaemia (like in Fig. 3), 30 (A) and 65 (B) min after organ isolation.

Parameters of assay: field $920 \pm 50 \mathrm{Gs}$, modulation amplitude $1 \mathrm{Gs}$, microwave power - $20 \mathrm{~mW}$ and frequency $2.63 \mathrm{GHz}$, sensitivity $500 \mu \mathrm{V} / \mathrm{pA}$, time constant $0.1 \mathrm{~s}$, and scan time $64 \mathrm{~s}$, average of 5 records (A), and 1 record (B). Arrows indicate the ${ }^{14} \mathrm{~N}$ hyperfine splitting.

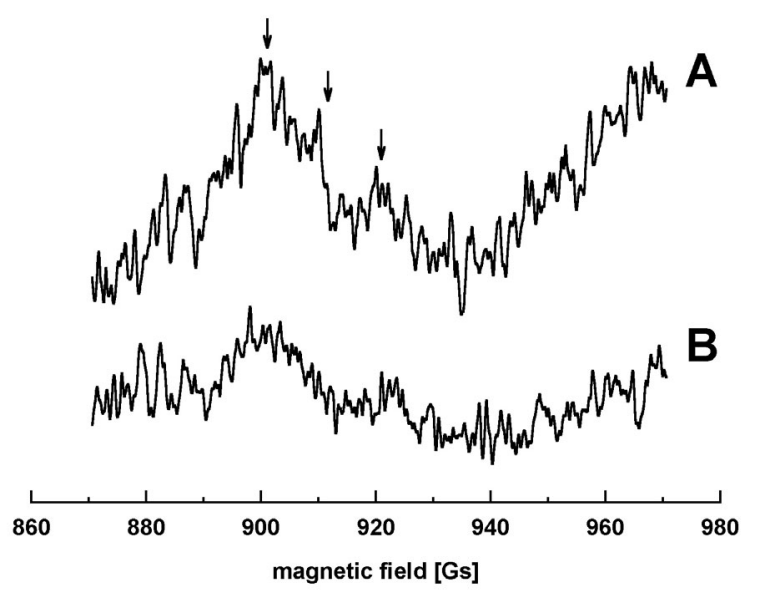

Figure 5. S-band EPR signals of whole murine lungs (about $400 \mathrm{mg}$ ) isolated at 6th hour of endotoxaemia (like in Fig. 3), 20 (A) and 40 (B) min after organ isolation.

Arrows and parameters of assay - see Fig. 4, except for sensitivity $2 \mathrm{mV} / \mathrm{nA}$.

\section{DISCUSSION}

The EPR spectrum of NO-Fe(DTCS) ${ }_{2}$ was observed in vitro only after reducing the reaction environment with an excess of sodium dithionite (Fig. 1). The signal was, however, pronounced both in liver homogenate (Fig. 3) and in the whole, extracted organ (Fig. 4) without the necessity of additional reduction of the samples. These results lead to the conclusion that formation of NO-Fe(DTCS) $)_{2}$ does not require additional reduction in vivo. Obviously, maintaining anaerobic environment would be necessary for in vitro experiments, e.g. in cell cultures. The existence of appropriate redox conditions in animal tissues in vivo, favouring the formation of nitrosyl-iron complexes with DETC, was postulated as early as the 1980s, by Vanin et al. (1984). Our results suggest its being the case for DTCS, and perhaps other iron(II) chelates.

The signal-to-noise ratio of the EPR spectrum of NO-Fe(DTCS $)_{2}$ detected in the liver was lower at X-band than at S-band (Fig. 3 vs. 
Fig. 4). This may be a consequence of experimenting at various microwave frequencies. The volume of the homogenate in the flat quartz cell used for X-band experiments was over eight times smaller than the volume of the whole liver measured at S-band. The filling factor was also lower for X-band than in the case of the isolated organ occupying a substantial fraction of the volume of the S-band cavity. Preparation of the liver for S-band measurement is simpler and generates fewer artifacts than would occur for experiments with homogenates at X-band. Although $\mathrm{Fe}(\mathrm{DTCS})_{2}$ is suitable for ${ }^{\circ} \mathrm{NO}$ spin trapping at X-band at room temperature, the clear advantage of ex vivo or in vivo measurement of -NO in isolated organs at lower frequencies needs to be explored further.

In contrast to the liver, the EPR NOFe(DTCS $)_{2}$ signals detected at S-band in the lung were hardly detectable and disappeared quickly (Fig. 5). At least three reasons of this phenomenon should be considered: the delay between euthanasia and EPR measurement, differences in the mass, and in the spin trap distribution between the organs. Indeed, the lung signal shown in Fig. 5A was recorded only 20 min after the moment of animal death when the level of spin adducts must have been higher. However, it was still 10 min earlier than the record of the pronounced signal of the liver (Fig. 4A). The low mass of the lung may imply that fewer paramagnetic centers were present in the measured sample, but at the same time it should increase the $Q$ value of the loaded cavity, as compared to the cavity loaded with the liver, which would improve sensitivity of the EPR assay at room temperature. Moreover, of all organs assayed, liver revealed the strongest EPR signals of NO-Fe(DETC) $)_{2}$ adducts detected at $77 \mathrm{~K}$ in samples of equal mass (Plonka et al., 2003). The higher hydrophobicity of DTCS, as compared to MGD, responsible for location of DTCS mainly in cell membranes, and for prolongation of its retention in the organism, seems to eliminate to some degree variability in distribution of the spin trap in various tissues.

There are a number of reports suggesting that lungs are particularly vulnerable to endotoxaemia (Plonka et al., 1999; Brigham \& Meyrick, 1986). Nitric oxide seems to protect the lung against LPS-induced injury (Chlopicki et al., 2001; Gryglewski et al., 1998; Brigham \& Meyrick, 1986), however, it contributes to lung injury when it combines with superoxide anions and forms peroxynitrite (Wizemann et al., 1994). It is well known that, beside particularly high expression of NOS-2 in the lung (Bune et al., 1995; Wizemann et al., 1994), endotoxaemia is associated with increased production of superoxide by NADPHoxidase or xanthine oxidase (Brandes et al., 1999). This may supplement the explanation of difficulties in the detection of NO-Fe(DTCS) 2 in the lung (Fig. 5), as compared to the liver (Fig. 4). If oxidative stress in the lung were really higher than that of the endotoxaemic liver, our results might illustrate the possibility to exploit NO-Fe(DTCS) ${ }_{2}$, and perhaps other nitrosyl-iron complexes, as indicators of redox properties of the tissue microenvironment, beside their conventional NO-metric application. This hypothesis certainly needs further investigation and some facts encourage us to undertake this effort. Firstly, endotoxaemic lungs represent the major site of neutrophil sequestration (Chlopicki et al., 2001). And secondly, in the alive, isolated, blood-perfused lung ex vivo, a weak "triplet" signal of nitrosohaemoglobin could only be detected after radical reduction of the whole system (the lung and the circulating blood) with an excess of sodium dithionite, as late as $5.5 \mathrm{~h}$ after LPS application (Plonka et al., 1999).

In conclusion, $\mathrm{Fe}(\mathrm{DTCS})_{2}$, a member of the family of DETC-derived Fe(II) chelates may serve as a convenient ${ }^{\circ} \mathrm{NO}$-metric agent for either X- or S-band EPR spectroscopy. The studies described here suggest the potential of using S-band EPR spectroscopy and Fe(DTCS) as an ${ }^{\circ}$ NO-metric technique to study ${ }^{\circ}$ NO pro- 
duction in isolated tissue preparations as large as a murine liver (about $1.5 \mathrm{~g}$ ).

\section{R E F E R E N C E S}

Brandes RP, Koddenberg G, Gwinner W, Kim D, Kruse HJ, Busse R, Mugge A. (1999) Role of increased production of superoxide anions by $\mathrm{NAD}(\mathrm{P}) \mathrm{H}$ oxidase and xanthine oxidase in prolonged endotoxemia. Hypertension.; 33: 1243-9.

Brigham KL, Meyrick B. (1986) Endotoxin and lung injury. Am Rev Respir Dis.; 133: 913-27.

Bune AJ, Shergill JK, Cammack R, Cook HT. (1995) L-Arginine depletion by arginase reduces nitric oxide production in endotoxic shock: an electron paramagnetic resonance study. FEBS Lett.; 366: 127-30.

Chlopicki S, Bartus JB, Walski M, Wolkow PP, Gryglewski RJ. (2001) Nitric oxide - a safeguard of pulmonary microcirculation in early endotoxaemia. In Nitric oxide. Basic research and clinical applications. Gryglewski RJ, Minuz P. eds, pp 137-48. OIS Press, Amsterdam.

Doi K, Akaike T, Fujii S, Tanaka S, Ikebe N, Beppu T, Shibahara S, Ogawa M, Maeda H. (1999) Induction of haem oxygenase-1 by nitric oxide and ischaemia in experimental solid tumors and implications for tumor growth. Br J Cancer.; 80: 1945-54.

Gryglewski RJ, Wolkow PP, Uracz W, Janowska E, Bartus JB, Balbatun O, Patton S, Brovkovych V, Malinski T. (1998) Protective role of pulmonary nitric oxide in the acute phase of endotoxemia in rats. Circ Res.; 82: 819-27.

Kubrina LN, Caldwell WS, Mordvintcev PI, Malenkova IV, Vanin AF. (1992) EPR evidence for nitric oxide production from guanidino nitrogens of L-arginine in animal tissues in vivo. Biochim Biophys Acta.; 1099: $233-7$.

McDonald CC, Philip WD, Mower HF. (1965) An electron spin resonance study of some com- plexes of iron, nitric oxide and anionic ligands. J Am Chem Soc.; 87: 3319-25.

Moncada S, Palmer RM, Higgs EA. (1991) Nitric oxide: physiology, pathophysiology, and pharmacology. Pharmacol Rev.; 43: 109-42.

Plonka PM, Chlopicki S, Plonka BK, Jawien J, Gryglewski RJ. (1999) Endotoxaemia in rats: detection of nitrosyl-haemoglobin in blood and lung by EPR. Curr Topics Biophys.; 23(1): $47-53$.

Plonka PM, Chlopicki S, Wisniewska M, Plonka BK. (2003) Kinetics of increased generation of ${ }^{\bullet} \mathrm{NO}$ in endotoxaemic rats as measured by EPR. Acta Biochim Polon.; 50: 807-814.

Pou S, Tsai P, Porasuphatana S, Halpern HJ, Chandramouli GV, Barth ED, Rosen GM. (1999) Spin trapping of nitric oxide by ferro-chelates: kinetic and in vivo pharmacokinetic studies. Biochim Biophys Acta.; 1427: 216-26.

Rosen GM, Britigan BE, Halpern HJ, Pou S. (1999) Free radicals: biology and detection by spin trapping. Oxford University Press, New York.

Shinobu LA, Jones SG, Jones MM. (1984) Sodium $N$-methyl-D-glucamine dithiocarbamate and cadmium intoxication. Acta Pharmacol Toxicol.; 54: 189-94.

Thiemermann C. (1997) Nitric oxide and septic shock. Gen Pharmacol.; 29: 159-66.

Vanin AF, Mordvintcev PI, Kleschyov AL. (1984) Appearance of nitric oxide in animal tissues in vivo. Studia Biophys.; 102: 135-43 (in Russian).

Vanin AF, Kubrina LN, Kurbanov IS, Mordvintcev PI, Khrapova NV, Galagan ME, Matkhanov EI. (1989) Iron as an inducer of nitric oxide formation in animal organisms. Biokhimia.; 54: 1974-9 (in Russian).

Weil JA, Bolton JR, Wertz JE. (1994) Electron paramagnetic resonance - elementary theory and practical applications. Wiley-Interscience, New York.

Wizemann TM, Gardner CR, Laskin JD, Quinones S, Durham SK, Goller NL, Ohnishi ST, Laskin DL. (1994) Production of nitric 
oxide and peroxynitrite in the lung during acute endotoxemia. J Leukoc Biol.; 56: 759-68.

Yoshimura T, Yokoyama H, Fuji S, Takayama F, Oikawa K, Kamada H. (1996) In vivo EPR detection and imaging of endogenous nitric oxide in lipopolysaccharide-treated mice. $\mathrm{Nat}$ Biotechnol.; 14: 992-4. 